\title{
Signatures of Polarimetric Parameters and their Implications on Land Cover Classification
}

\author{
Skriver, Henning
}

Published in:

IGARSS: 2007 IEEE INTERNATIONAL GEOSCIENCE AND REMOTE SENSING SYMPOSIUM

Link to article, DOI:

10.1109/IGARSS.2007.4423775

Publication date:

2007

Document Version

Publisher's PDF, also known as Version of record

Link back to DTU Orbit

Citation (APA):

Skriver, $H$. (2007). Signatures of Polarimetric Parameters and their Implications on Land Cover Classification. In IGARSS: 2007 IEEE INTERNATIONAL GEOSCIENCE AND REMOTE SENSING SYMPOSIUM: SENSING

AND UNDERSTANDING OUR PLANET (pp. 4195-4198). IEEE. https://doi.org/10.1109/IGARSS.2007.4423775

\section{General rights}

Copyright and moral rights for the publications made accessible in the public portal are retained by the authors and/or other copyright owners and it is a condition of accessing publications that users recognise and abide by the legal requirements associated with these rights.

- Users may download and print one copy of any publication from the public portal for the purpose of private study or research.

- You may not further distribute the material or use it for any profit-making activity or commercial gain

- You may freely distribute the URL identifying the publication in the public portal 


\title{
Signatures of Polarimetric Parameters and their Implications on Land Cover Classification
}

\author{
Henning Skriver \\ Danish National Space Center \\ Technical University of Denmark, Lyngby, Denmark \\ hs@space.dtu.dk
}

\begin{abstract}
Knowledge-based or rule-based classification schemes provide robust classification of normally a few major classes. In order to determine optimum polarimetric parameters for such classification schemes, a study has been performed, where the separability between different sets of major classes using many different polarimetric parameters has been investigated using airborne, $C$ - and L-band polarimetric SAR data.
\end{abstract}

Keywords: polarimetric SAR, classification, signatures, knowledge-based classification

\section{INTRODUCTION}

Land cover maps provide fundamental information to many aspects of land use planning and policy development, as a prerequisite for monitoring and modelling land use and environmental change, and as a basis for land use statistics at all levels. It is well known that remote sensing may provide important and valuable information about crops and other land cover classes. This is true for both optical/infrared and radar data, where radar data is especially important for regions where cloud cover is a problem. In this study, the focus has been on the use of polarimetric SAR data for robust land cover classification. Polarimetric SAR data will be available from satellites in the near future, e.g. the Japanese ALOS, the Canadian Radarsat-2 and the German TerraSAR-X.

Different approaches have been used to extract the land cover and crop information from polarimetric SAR data, i.e. statistical methods based on the Wishart distribution [1] or covariance matrix elements transformed into backscatter coefficients [2], methods based on scattering mechanisms [34], and knowledge-based methods [5-7]. In the latter approaches it is possible to include scattering model results and common knowledge about the targets. Hence, such methods are normally relatively robust and easy to adjust to different growing conditions caused by for instance different sowing time, soil and weather conditions. The number of different classes that can be determined is normally relatively small using this type of methods. The statistically based methods, on the other hand, will normally provide a larger number of classes, but the classifiers will then normally be specifically adjusted to the data set at hand, and it is difficult to adopt the classifier to other environmental conditions. The purpose of the analysis presented in this paper is to study signatures of polarimetric parameters in order to identify parameters that are suitable for the knowledge-based approach.

\section{DATA SET}

The data set used in this paper is from the Danish dualfrequency, fully polarimetric, airborne SAR system, EMISAR [8]. In 1998 a data set was acquired at the Foulum agricultural test site with multi-temporal acquisitions spanning the entire growing season, with simultaneous C- and L-band acquisitions on April $17^{\text {th }}$, May $20^{\text {th }}$, June $16^{\text {th }}$, and July $15^{\text {th }}$. The classes present in the data set are spring crops: beets, peas, potatoes, maize, spring barley, and oats, winter crops: rye, winter barley, winter wheat, winter rape, and grass, forests: Norway spruce, Caucasian Fir, and a mixture of deciduous trees, and lakes

\section{METHODOLOGY}

The basis for the knowledge-based methods is that a single or a few parameters exist that provide a very clear discrimination between some major classes. In order to find such parameters an extensive study of the separability between classes using a single parameter has been carried out. The socalled Jeffries Matusita distance has been evaluated for all parameters. The most promising parameters have then been plotted as a function of incidence angle to further evaluate their potential for discrimination.

\section{SEPARABILITY USING POLARIMETRIC PARAMETERS}

The Jeffries-Matusita distance provides numbers between 0 and 2, where $0-1$ corresponds to very poor separability, 1-1.5 corresponds to poor separability, and 1.5-2 corresponds to high separability. The parameters studied are the following:

$\begin{array}{lll}\text { 1. } & \sigma_{\mathrm{hh}}^{0} & \text { Sigma backscatter coefficient, HH-polarisation } \\ \text { 2. } & \sigma_{\mathrm{vv}}^{0} & \text { Sigma backscatter coefficient, VV-polarisation } \\ \text { 3. } & \sigma_{\mathrm{hv}}^{0} & \text { Sigma backscatter coefficient, HV-polarisation } \\ \text { 4. } & \gamma_{\mathrm{hh}}^{0} & \text { Gamma backscatter coefficient, HH-polarisation } \\ \text { 5. } & \gamma_{\mathrm{vv}}^{0} & \text { Gamma backscatter coefficient, VV-polarisation } \\ \text { 6. } & \gamma_{\mathrm{hv}}^{0} & \text { Gamma backscatter coefficient, HV-polarisation } \\ \text { 7. } & \sigma_{\mathrm{hhvv}}^{0} & \text { Sigma backscatter coefficient, HHVV-pol. } \\ \text { 8. } & \phi_{\mathrm{hhv}} & \text { Phase difference between HH and VV pol. } \\ \text { 9. } & \rho_{\mathrm{hhvv}} & \text { Correlation coefficient between HH and VV pol. } \\ \text { 10. } & \sigma_{\mathrm{vv}}^{0} / \sigma_{\mathrm{hh}}^{0} & \text { Ratio between VV and HH backscatter coeff. } \\ \text { 11. } & \sigma_{\mathrm{hv}}^{0} / \sigma_{\mathrm{hh}}^{0} & \text { Ratio between HV and HH backscatter coeff. } \\ \text { 12. } & \sigma_{\mathrm{hv}}^{0} / \sigma_{\mathrm{vv}}^{0} & \text { Ratio between HV and VV backscatter coeff. }\end{array}$



13. $\sigma_{\mathrm{rr}}^{0}$
14. $\sigma_{11}^{0}$
Sigma backscatter coefficient, RR-polarisation
15. $\sigma_{\mathrm{rl}}^{0}$
16. $\sigma_{\mathrm{rr}}^{0} / \sigma_{11}^{0}$
Sigma backscatter coefficient, LL-polarisation
17. $\sigma_{\mathrm{rr}}^{0} / \sigma_{\mathrm{rl}}^{0}$
18. $\sigma_{11}^{0} / \sigma_{\mathrm{rl}}^{0}$
19. $\sigma_{++45}^{0}$
20. $\sigma_{+-45}^{0}$
Sigma backscatter coefficient, RL-polarisation
Ratio between RR and LL backscatter coeff.
Ratio between RR and RL backscatter coeff.
Ratio between LL and RL backscatter coeff.
Sigma backscatter coeff., $45^{\circ}$ linear co-pol.
21. $\sigma_{+-45}^{0} / \sigma_{++45}^{0}$ Ratio between $45^{\circ}$ linear co- and cross-pol.
22. $\mathrm{H}$ Entropy
23. A Anisotropy
24. $\alpha \quad$ Alpha angle
25. $\beta \quad$ Beta angle
26. $\delta \quad$ Delta angle
27. $\gamma \quad$ Gamma angle
28. Depol Depolarisation ratio
29. Sym Symmetry parameters
30. $\gamma_{\mathrm{rr}}^{0}$ Gamma backscatter coefficient, RR-polarisation
31. $\gamma_{11}^{0}$
32. $\gamma_{\mathrm{rl}}^{0}$
33. $\gamma_{++45}^{0}$
34. $\gamma_{+-45}^{0}$
35. $\gamma_{-45}^{0}$
36. $\gamma_{\mathrm{h}+45}^{0}$
37. $\gamma_{\mathrm{hl}}^{0}$
38. $\gamma_{+451}^{0}$
Gamma backscatter coefficient, LL-polarisation
Gamma backscatter coefficient, RL-polarisation
Gamma backscatter coefficient, $+45+45$-pol.
Gamma backscatter coefficient, $+45-45$-pol.
Gamma backscatter coefficient, -45-45-pol.
Gamma backscatter coefficient, $\mathrm{H}+45$-pol.
Gamma backscatter coefficient, HL-pol.
39. $\gamma_{+451}^{0}+\gamma_{-45 \mathrm{r}}^{0}$ Gamma backscatter coeff., $+45 \mathrm{~L}+-45 \mathrm{R}-$ pol.
40. $\gamma_{+45 \mathrm{r}}^{0}+\gamma_{-451}^{0}$ Gamma backscatter coeff., $+45 \mathrm{R}+-45 \mathrm{~L}-$ pol.
41. $\mathrm{P}_{\text {volume }} \quad$ Volume power (Freeman/Durden decom.)
42. $\mathrm{P}_{\text {surface }}$
43. $\mathrm{P}_{\mathrm{dbounce}}$
Surface power (Freeman/Durden decom.)
44. $\mathrm{P}_{\text {total }}$
Double bounce power (Freeman/Durden decom.)
Total power (Freeman/Durden decom.)

Included in the list of parameters are the linear polarisation backscatter coefficients (1-6) and their ratios (10-12), circular polarisation backscatter coefficients (13-15 and 30-32) and their ratios (16-18), 45 ${ }^{\circ}$ linear co- and cross-polarisation backscatter coefficients (19-20 and 33-35) and a ratio (21), as well as backscatter coefficients with other combinations of transmit and receive polarisations (36-40), which are used in the Hoekman and Vissers classification method [2]. Also, included are the phase difference and correlation coefficient for the $\mathrm{HH}$ and VV polarisations (8-9), the Cloude and Pottier decomposition parameters (22-27) [3] and the Freeman and Durden decomposition parameters (41-44) [4].

\section{A. Main land cover classes}

The classes are grouped into two groups, i.e. crops and forest, and the Jeffries-Matusita distance is then computed for all of the above parameters for each acquisition and for both $\mathrm{C}$ and L-band. The results of these computations are shown in Figs. 1 and 2 for C- and L-band, respectively. It can be seen that the separability is larger at L-band than at C-band. The parameters, especially at L-band, that provide the largest discrimination are the backscatter coefficient parameters. At
C-band it is the May acquisition and to some extent the April acquisition that provide the best discrimination. At L-band all four acquisitions provide high discrimination, with some preference to the April and May acquisitions.

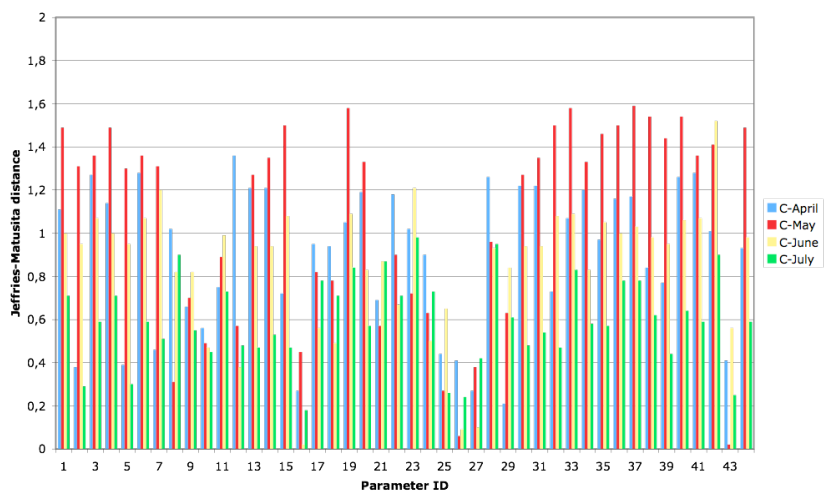

Figure 1. Jeffries-Matusita distance for crops vs. forest at C-band.

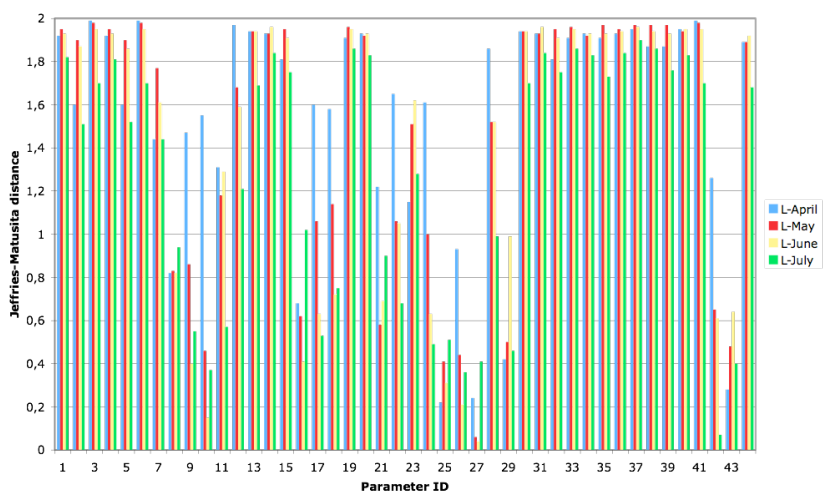

Figure 2. Jeffries-Matusita distance for crops vs. forest at L-band.

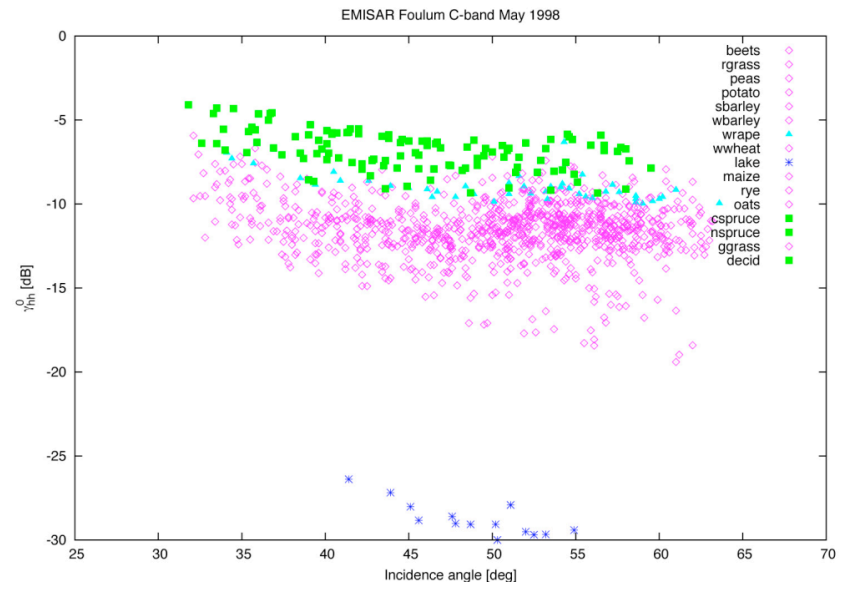

Figure 3. $\quad \gamma_{\text {hh }}^{0}$ parameter vs. incidence angle (May, C-band, Crops/Forest)..

One of the parameters with large distances at C-band, the $\gamma_{\mathrm{hh}}^{0}$ parameter in May, is shown in Fig. 3. It is seen that the forest is to a large degree separated from the other classes, but it is, however, not a very clear and distinct separation. Also, it can be seen that the threshold between the forest and the crop classes varies with incidence angle. 
At L-band, the $\gamma_{\text {hv }}^{0}$ parameter in April (and in May) provides a fairly large discrimination, which is also seen from the plot of the $\gamma_{\mathrm{hv}}^{0}$ parameter vs. incidence angle in Fig. 4. Some overlap between the forest classes and the winter rape is however seen. From Fig. 5 it is seen that for instance the parameter $\gamma_{+45+45}^{0}$ in July may discriminate between forest and rape. A scatter plot in Fig. 6 between the two parameters, $\gamma_{\text {hv }}^{0}$ in April and $\gamma_{+45+45}^{0}$ in July, shows the potential for a clear discrimination between forested areas and other areas using a simple classification rule $\left(\gamma_{+45+45}^{0}=-1.75 \gamma_{\mathrm{hv}}^{0}-35\right)$.

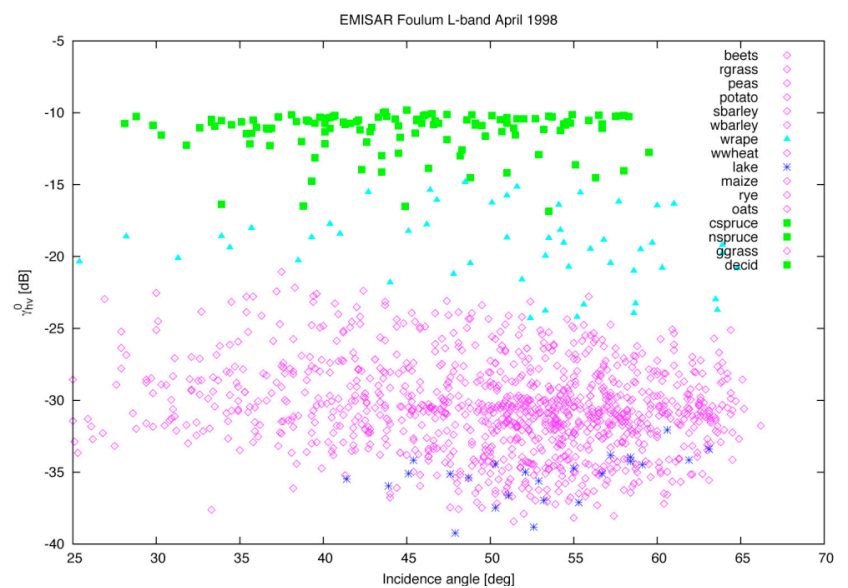

Figure 4. $\gamma_{\text {hh }}^{0}$ parameter vs. incidence angle (April, L-band, Crops/Forest).

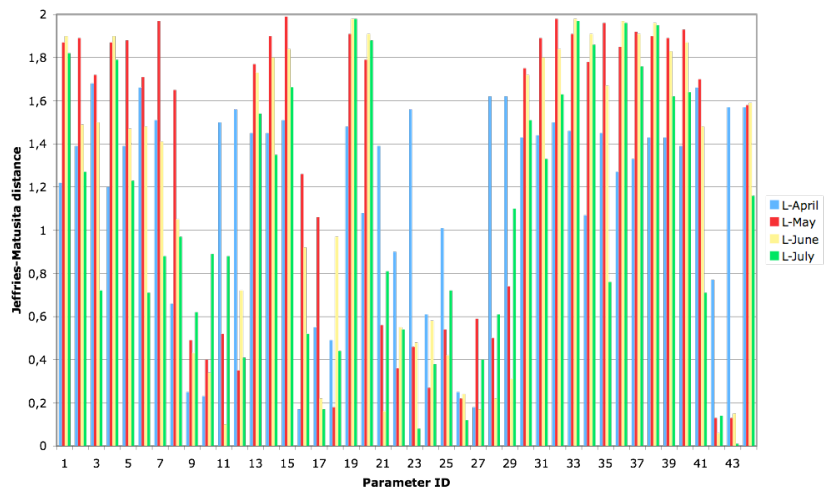

Figure 5. Jeffries-Matusita distance for winter rape vs. forest at L-band.

The same type of investigation can be carried out for the lake areas. At C-band it is found, that all the backscatter coefficient parameters at all acquisitions can be used to discriminate between the lake areas and the surroundings. The reason is that the lake areas are smooth, and all the surrounding areas are fairly rough, especially at C-band. At L-band, the best acquisition for this discrimination is July using most of the backscatter coefficient parameters.

\section{B. Spring/winter crop classes}

The discrimination between spring crops and winter crops is based on the large difference in the scattering mechanisms for bare soil and vegetation, which distinguish the two types of crops in the beginning of the growing season. In Figs. 7 and 8 are shown the Jeffries-Matusita distances for the discrimination between the two types of crops for C- and L-band, respectively

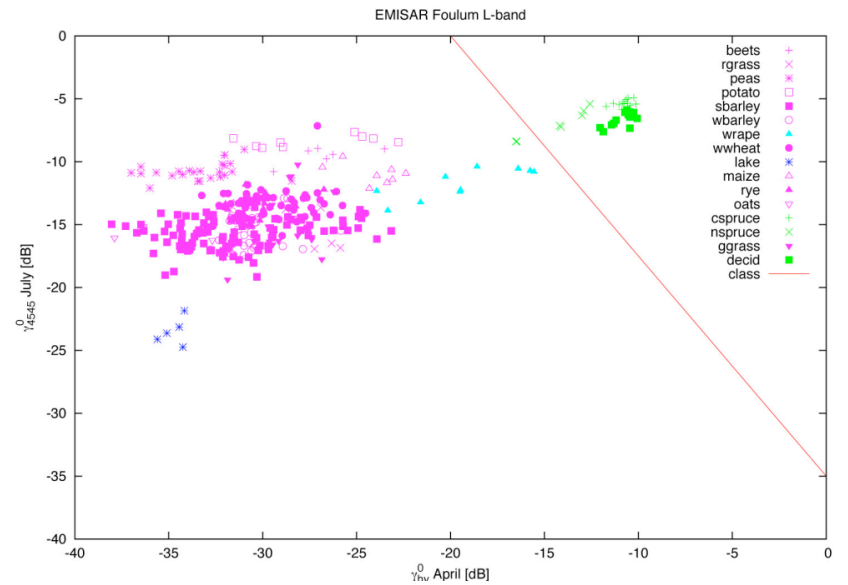

Figure 6. Scatterplot between $\gamma_{\text {hv }}^{0}$ in April and $\gamma_{+45+45}^{0}$ in July at L-band

At C-band, it is clearly the early acquisition, i.e. in April, that has a high discrimination potential. The parameters with a large distance are e.g., $\sigma_{\mathrm{hv}}^{0} / \sigma_{\mathrm{vv}}^{0}$, Entropy, $\rho_{\text {hhvv }}$, and $\sigma_{\mathrm{ll}}^{0} / \sigma_{\mathrm{rl}}^{0}$. Clearly, these are parameters that provide a large difference between surface scattering and depolarisation in the vegetation. In Fig. 9 is shown the $\sigma_{\mathrm{hv}}^{0} / \sigma_{\mathrm{vv}}^{0}$ parameter as a function of incidence angle, and it is seen that it is possible to use this parameter in a simple classification rule

From the Jeffries-Matusita distances for the L-band acquisitions it is seen that the acquisition in May has the largest potential in discriminating between spring and winter crops. The difference in acquisition compared to C-band is most likely because the vegetation must be larger at L-band compared to $\mathrm{C}$-band to provide a difference between bare and vegetated fields, due to the larger penetration depth at L-band. The parameters with largest potential are the $\gamma_{11}^{0}, \gamma_{+-45}^{0}$, and $\gamma_{+45 \mathrm{r}}^{0}+\gamma_{-451}^{0}$, but no clear separation between winter and spring crops are found for these parameters.

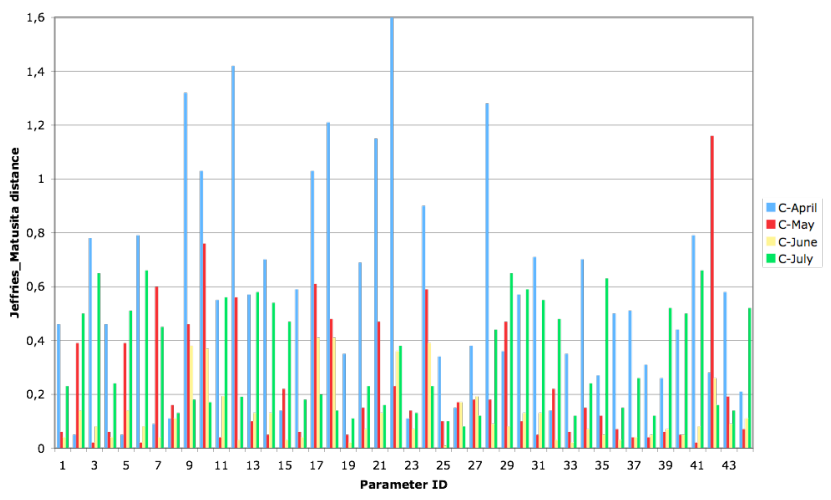

Figure 7. Jeffries-Matusita distance for spring vs. winter crops at C-band.

\section{Broad leaves/small stem crop classes}

Another type of separation based on structural differences is the separation between broad leaves crops (e.g. beets, and 
potatoes) and small stem crops (e.g. cereals, and peas). At the Foulum test site, the broad leaves crops are beets, potatoes and maize, and the small stem crops are spring barley, oats and peas. In Figs. 10 and 11 are shown the Jeffries-Matusita differences for C- and L-band, respectively

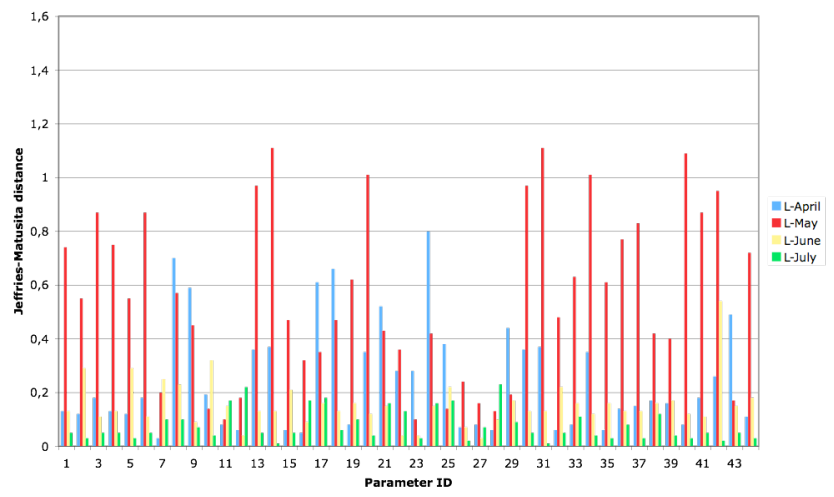

Figure 8. Jeffries-Matusita distance for spring vs. winter crops at L-band.

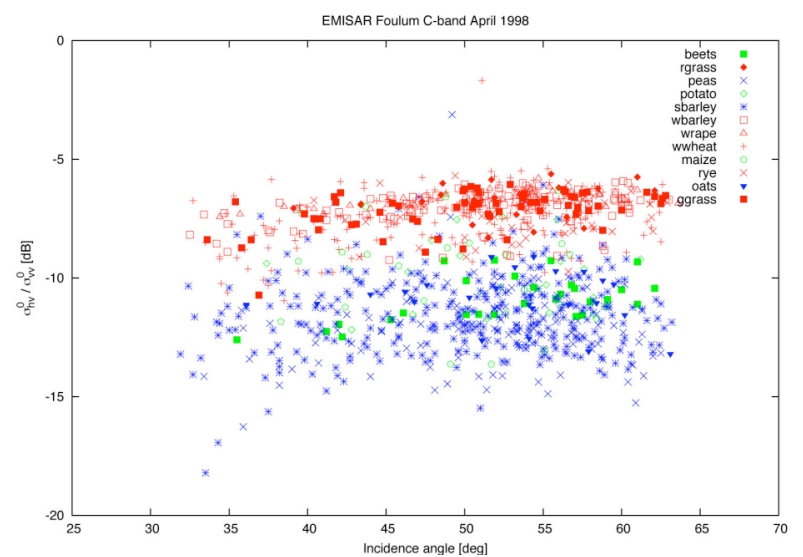

Figure 9. $\sigma_{\mathrm{hv}}^{0} / \sigma_{\mathrm{vv}}^{0}$ vs. inc. angle (April, C-band, Spring/Winter crops).

At C-band, it is primarily the May acquisition that provides the largest discrimination potential. For this acquisition, the parameters with the largest difference are $\gamma_{\mathrm{hv}}^{0}, \sigma_{\mathrm{hv}}^{0} / \sigma_{\mathrm{vv}}^{0}$, Entropy, $P_{\text {volume }}, \rho_{\text {hhvv }}, \gamma_{\mathrm{rr}}^{0}, \gamma_{11}^{0}$, and $\gamma_{11}^{0} / \gamma_{\mathrm{rl}}^{0}$, and it is found that these parameters clearly show clear potential for separation.

At L-band, the distances are smaller than at C-band. The largest distances are seen at the May and July acquisitions. The potential classification rule between the two types is very much dependent on the incidence angle for the parameters in May. It is more difficult to establish a clear classification at L-band.

\section{CONCLUSIONS}

In conclusion about the discrimination of the major land cover classes, it is clear from the above analysis that it is possible to discriminate between agricultural areas, forest areas, and lake areas using simple parameters, especially at Lband. A crop classification scheme where the first step is to separate between spring and winter crops in an early acquisition is clearly feasible at C-band, where the results show that several parameters can be used to perform this separation.
For L-band, a clear separation is, however, not possible. For the separation between broad leaves and small stem crops, the best parameters are found at C-band in May, and the separability is relatively small at L-band.

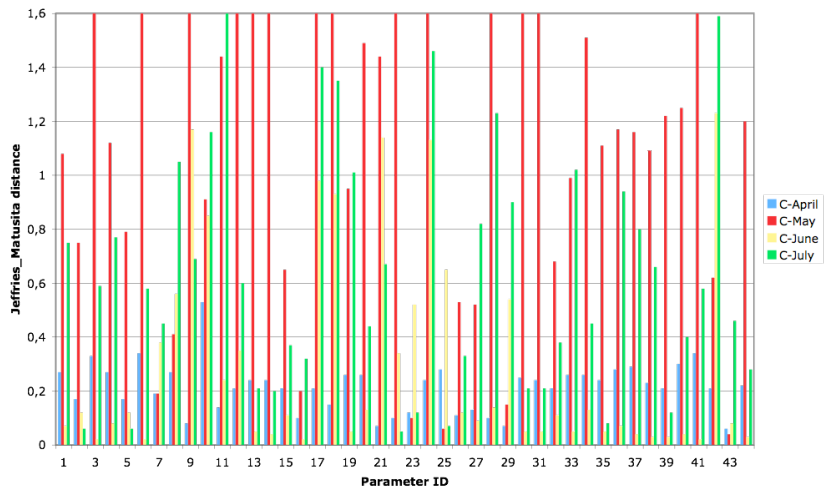

Figure 10. Jeffries-Matusita dist. for broad leaves/small stem crops at C-band.

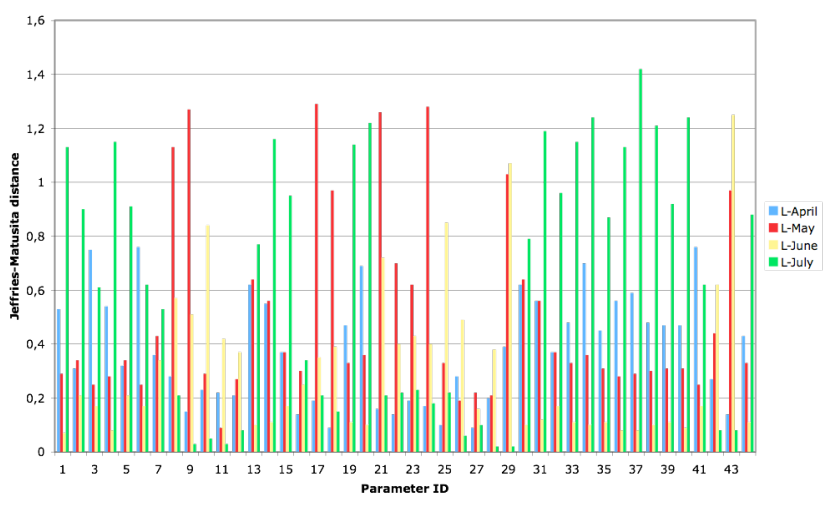

Figure 11. Jeffries-Matusita dist. for broad leaves/small stem crops at L-band.

\section{REFERENCES}

[1] Lee, J.S., M.R. Grunes, and R. Kwok, "Classification of multi-look polarimetric SAR imagery based on complex Wishart distribution", International Journal of Remote Sensing, vol. 15, pp. 2299-2311, 1994.

[2] Hoekman, D.H., and M.A.M. Vissers, “A new polarimetric classification approach evaluated for agricultural crops", IEEE Trans. Geosci. Rem. Sens., vol. 41, pp. 2881-2889, 2003.

[3] Cloude, S.R., and E. Pottier, "An entropy based classification scheme for land applications of polarimetric SAR", IEEE Trans. Geosci. Rem. Sens., vol. 35, 68-78, 1997.

[4] Freeman, A., and S.L. Durden, "A three-component scattering model for polarimetric SAR data”, IEEE Trans. Geosci. Rem. Sens., vol. 36, pp. 963-973, 1998.

[5] Pierce, L.E., F.T. Ulaby, K. Sarabandi, and M.C. Dobson," Knowledgebased classification of polarimetric SAR images", IEEE Trans. Geosci. Rem. Sens., vol. 32, pp. 1081-1086, 1994.

[6] Skriver, H., "Land-cover map information from polarimetric SAR using knowledge-based techniques", 3rd Int. Symp. on Retrieval of Bio- and Geophysical Parameters from SAR data for Land Applications, 2001.

[7] Ferrazzoli, P., L. Guerriero, and G. Schiavon, "Experimental and model investigation on radar classification capability", IEEE Trans. Geosci. Rem. Sens., vol. 37, pp. 960-968, 1999.

[8] Christensen, E. L., N. Skou, J. Dall, K. Woelders, A. Netterstrøm, J.H. Jørgensen, J. Granholm, and S.N. Madsen, 1998, "EMISAR: Polarimetric L- and C-band SAR", IEEE Trans. Geosci. Rem. Sens., vol. 36, pp. 1852-1865. 